\title{
Simultaneous Water Purification and Energy Production in a Microbial Desalination Cell
}

\author{
Abdelsalam Elawwad ${ }^{\mathbf{1}}$, Mostafa Ragab ${ }^{\mathbf{1}}$ \\ ${ }^{1}$ Environmental Engineering Dept., Faculty of Engineering, Cairo University \\ El-Gamaa St., 12613 Giza, Egypt \\ elawwad@cu.edu.eg \\ ${ }^{2}$ Sanitary and Environmental Engineering Institute, Housing and Building National Research Center \\ 87 Tahir St., Dokki, 11511 Giza, Egypt \\ mostafa.ragab@giz.de
}

\begin{abstract}
Current desalination and wastewater treatment technologies are consuming a lot of energy due to the energy needed for aeration, sludge treatment, thermally driven distillation, or high-pressure membrane operation. The microbial desalination cells (MDCs) are innovative technology which integrates the microbial fuel cells process and electrodialysis for water desalination, production of renewable energy and wastewater treatment. In MDCs, electrical energy is extracted from wastewater by the action of microbial extracellular respiration and at the same time used to drive the desalination process. In this Paper, lab-scale MDC was tested at ambient temperature for simultaneous wastewater treatment, water desalination and energy production. Voltage production during the experimental period was stable with an average and a maximum voltage of 100 and $183 \mathrm{mv}$, respectively. COD and TDS removals were 83 and $20 \%$, respectively. The average calculated CE was $18.4 \%$ over the experimental period.
\end{abstract}

Keywords: Wastewater Treatment; Desalination, Microbial Desalination Cells, Electricity Generation.

\section{Introduction}

Considering the water scarcity all over the world, desalination of brackish water and seawater has been increasingly used in the last decades [1]. However, the use of recent desalination technologies is limited because of the high energy consumption [2]. Current commercially available desalination technologies that are widely applied can be divided into two kinds: membrane and thermal processes. Even the representing membrane process, reverse osmosis (RO) which requires much less energy than thermal processes, have an energy demand of $3.7 \mathrm{~kW} \mathrm{~h} \mathrm{~m}^{-3}$ [3]. This energy cost can contribute to approximately $30-44 \%$ of water production cost [2]. For example, a 50 MGD Reverse Osmosis (RO) plant treating seawater, annualized capital costs make up $37 \%$ on average from the annual cost breakdown of the plant [4].

Although the idea of indirect energy harvesting from wastewater is well known through methane production in anaerobic technologies, such as UASB [5]. In recent years, different innovative bioelectrochemical systems for direct energy harvesting from wastewater, such as microbial fuel cells (MFCs) emerged as a promising technology for simultaneous energy production and wastewater treatment. Microbial desalination cells (MDCs) is a new innovative desalination technology that uses the energy in wastewater to desalinate seawater while also generate electricity [6]. It is estimated that the maximum attainable energy in wastewater extracted from organic oxidation to $\mathrm{CO}_{2}$ and $\mathrm{H}_{2} \mathrm{O}$ is $1.93 \mathrm{kWh} \mathrm{m}^{-3}$ [7]. MDCs is growing technology developed to accomplish wastewater treatment and seawater desalination in a single reactor $[8,9]$.

The MDC consists of an anode chamber and a cathode chamber separated by ion-exchange membranes (anion and cation-exchange membranes). The ion-exchange membranes surround the salt solution to make a desalination chamber. The wastewater containing the organic matter enters the anodic side where biofilm is formed due to the proliferation of the bacteria which oxidize organic matter, producing electrons at the electrode and releasing protons into solution. Then, the produced electrons move through an external resistance to the electron acceptor at the cathode, most commonly oxygen which is reduced to water. Theoretically, as one mole of electrons passes through the circuit, one mole of sodium chloride molecules dissociates with one mole of chloride passing through the anion-exchange membrane to the anode chamber and one mole of sodium passing the cation-exchange membrane to the cathode chamber. This leaves a desalinated solution in the middle chamber $[8,10,11]$. 
The MDCs are new-born technology and still needs a lot of research, development and improvement to fully understand the mechanism of treatment and desalination, the appropriate bacterial biomass, the optimum operating conditions, the utmost efficiency...etc. before proceeding to a full-scale application. The research aims at introducing new sustainable technology with low-cost energy and environment-friendly for both desalination of saline water and treatment of wastewater. The proposed system can also generate direct electricity. In this research, design, manufacture and identifying the characterization of a bench scale of a low-cost, and efficient desalination and wastewater treatment system is taken place. MDC was tested at ambient temperature for five consecutive operational cycles. The preliminary results obtained from this research will help us to design further research which will focus on the examining the technical and economic feasibility of this system, examining the long-term operation of the system in terms of electrodes and membranes performance and their sustainability, scaling up recommendations for the continuous operation and regular maintenance requirements.

\section{Materials and Methods}

Microbial Desalination Cells (MDCs) is constructed with the configurations illustrated in Figure 1 using a transparent inert acrylic plastic. The dimensions for MDCs are $(20 \mathrm{~cm}$ length $\times 8 \mathrm{~cm}$ height $\times 6 \mathrm{~cm}$ width). Necessary holes will be made to put the measurement probes of the data acquisition system, inlet and outlet of the solutions. The three chambers are separated with ion-exchange membranes: a cation-exchange membrane between the cathode chamber and the desalination chamber and an anion-exchange membrane between the anode chamber and the desalination chamber. Anode and cathode electrodes are coupled titanium wire and inserted into the anode and cathode chambers respectively. The circuit between both electrodes is closed via an external resistance (100 $\Omega$ ).

The system was seeded from another well operated MDC. Then it was tested under batch flow regimes for consecutive five operational cycles. The cell voltage was recorded every 2 minutes by the voltage probe connected to the data acquisition system (DAQ) from Vernier (USA). The total dissolved solids and $\mathrm{pH}$ will be measured with the salinity sensor and $\mathrm{pH}$ probe respectively connected to the DAQ every one-hour. COD in raw water was $820 \mathrm{mg} \mathrm{L}^{-1} \mathrm{on}$ average. COD was determined using the spectrophotometer at the end of each desalination cycle. All experiments will be conducted at room temperature $\left(25^{\circ} \mathrm{C}\right.$ ) with normal atmospheric pressure and humidity as described by (Sevda et al., 2017). Columbic efficiency (CE) in one desalination cycle is described as the ratio between the output charge "Qout" to the input charge " $\mathrm{Q}_{\mathrm{in}}$ ". The output charge is calculated by integrating the current over time.

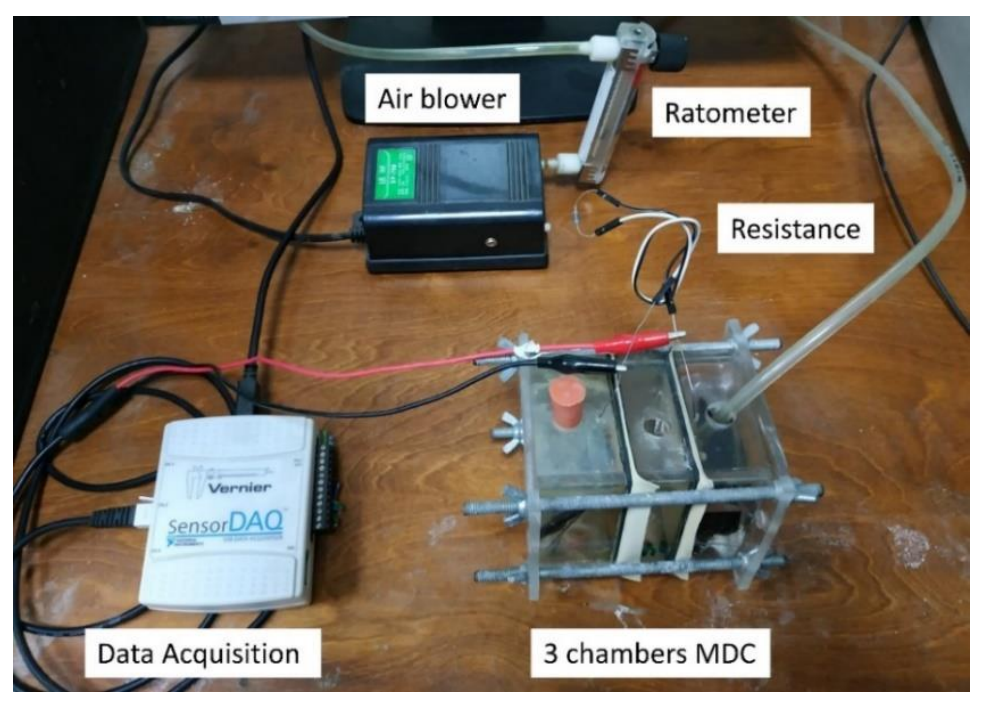

Fig. 1: Three-chamber desalination MDC and the data acquisition system.

\section{Results}

Figure 2 represents the voltage results over the different operational cycles. The average voltage was $100 \mathrm{mv}$ with a maximum voltage of $183 \mathrm{mv}$. The current is calculated according to the Ohm's law and it was $0.75 \mathrm{~mA}$ on average. Table 1 shows COD and TDS data during the different operational cycles. Figure 3 summarizes the COD and 
desalination efficiency over the different operational cycles. The average COD and desalination efficiencies were $83 \%$ and $20 \%$, respectively. The average calculated CE was $18.4 \%$ over the experimental period.

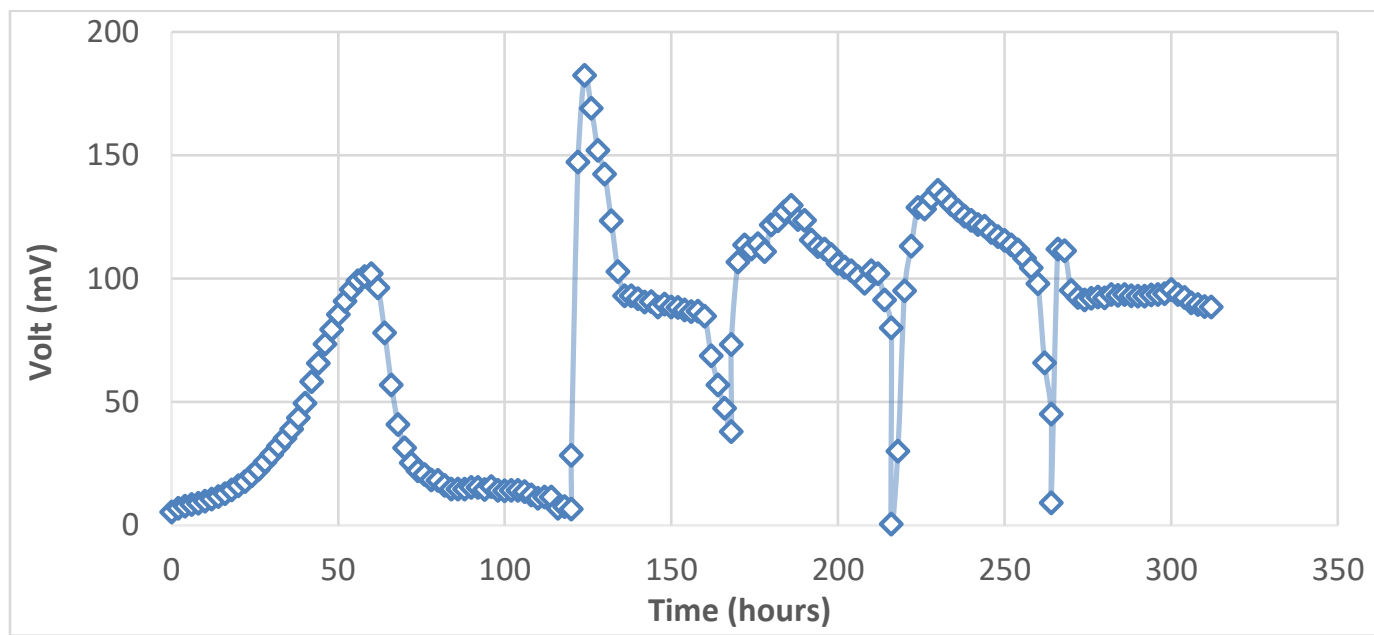

Fig. 2: Generated voltage from MDC in millivolt.

Table 1: COD and TDS data over the experimental period.

\begin{tabular}{|c|c|c|c|c|c|c|c|c|}
\hline \multirow{2}{*}{ Parameter } & \multicolumn{9}{|c|}{ COD } & \multicolumn{3}{c|}{ TDS } \\
\cline { 2 - 8 } & in & out & $\begin{array}{c}\text { Removal } \\
\text { Eff. (\%) }\end{array}$ & $\begin{array}{c}\text { Removal } \\
\text { Rate (g/L/d) }\end{array}$ & in & out & $\begin{array}{c}\text { Removal } \\
\text { Eff. (\%) }\end{array}$ & $\begin{array}{c}\text { Removal } \\
\text { Rate (g/L/d) }\end{array}$ \\
\hline Cycle No. 1 & 960 & 93.1 & 90.3 & 0.87 & 21,000 & 14,645 & 30.3 & 10.1 \\
\hline Cycle No. 2 & 785.3 & 174.7 & 77.8 & 1.53 & 20,000 & 17,675 & 11.6 & 9.2 \\
\hline Cycle No. 3 & 612.5 & 138.2 & 77.4 & 1.19 & 20,300 & 16,968 & 16.4 & 13.2 \\
\hline Cycle No. 4 & 864 & 178.6 & 79.3 & 1.71 & 20,000 & 14,847 & 25.8 & 20.5 \\
\hline Cycle No. 5 & 876.5 & 100.8 & 88.5 & 1.94 & 20,000 & 16,665 & 16.7 & 13.2 \\
\hline
\end{tabular}

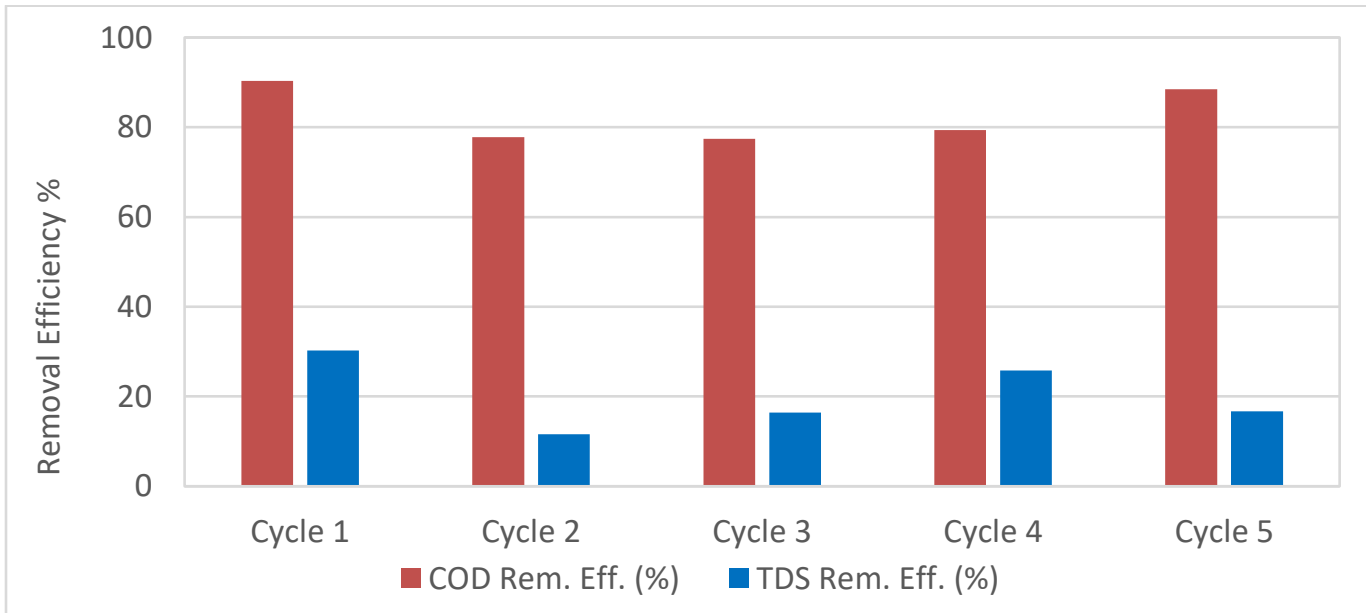

Fig. 3: COD and TDS removal efficiencies over the different operation cycles.

The operation of this lab-scale MDC will be continued for a longer time. The results and stability of the system after the long-term operation will be presented at the conference. The amount of electrical current generated, Columbic Efficiency, and Internal Resistance will be calculated and presented. Total energy production will be determined and correlated to water desalination capacity ( $\mathrm{KW} \mathrm{h} / \mathrm{m}^{3}$ desalinated water) or COD removal ( $\mathrm{KW} \mathrm{h} / \mathrm{kg} \mathrm{COD} \mathrm{removal).}$ 
The proposed system integrates the expertise and skills of desalination system experts and wastewater treatment experts. The technical impacts of the research will be manifested in designing and building a system produces fresh water and treating the wastewater which can function at different levels of input water salinity and wastewater strength according to the source of water. Discharge of untreated wastewater to water bodies in small communities is one of the major environmental problems [12]. This technology could be a promising option for decentralized areas which suffer from lack of appropriate water and sanitation services in many countries [13]. Moreover, the success of the proposed technology will have a direct impact on the development of a novel desalination system and will be added value in both environmental and economic aspects.

\section{Conclusion}

This system is environmentally friendly and may be part of the green building systems in the future. The system has minimal operation and maintenance requirements, due to minimal energy and equipment requirements. The proposed system relies upon green energy and renewable resources, which in turn reduces the running cost compared to conventional wastewater treatment and desalination systems. This technology may provide a valuable solution for problems of potable water shortage and high energy costs. However, it is noteworthy that this novel technology is still fundamental and needs extensive research, development and improvement. Further data collection is required to increase the accuracy of the experimental results.

\section{References}

[1] Q. Ping, “Advancing Microbial Desalination Cell towards Practical Applications," Ph.D. dissertation, Virginia Tech, 2016.

[2] R. Semiat, "Energy Issues in Desalination Processes," Envir. Sci. Tech., vol. 42, no. 22, pp. 8193-8201, 2008.

[3] M. Mehanna, P. D. Kiely, D. F. Call, B. E. Logan, "A microbial electrodialysis cell for simultaneous water desalination and hydrogen gas production," Envir. Sci. Tech., vol. 44, no. 24, pp. 9578-9583, 2010.

[4] H. Cooley, N. Ajami, "Key Issues for Seawater Desalination in California: Cost and Financing: Pacific Institute for Studies in Development," Environment \& Security, 2012.

[5] A. Elawwad, M. Hazem, "Minimization of sludge production in an integrated UASB-continuous flow sequencing batch reactor system," Desalin. Water. Treat., vol. 91, pp. 206-213, 2017.

[6] R. J. Davis, Y. Kim, B. E. Logan, "Increasing desalination by mitigating anolyte pH imbalance using catholyte effluent addition in a multi-anode bench scale microbial desalination cell," ACS Sustain. Chem. Eng., vol. 1, no. 9, pp. 12001206, 2013.

[7] K. Zuo, F. Liu, S. Ren, X. Zhang, P. Liang, X. Huang, "A novel multi-stage microbial desalination cell for simultaneous desalination and enhanced organics and nitrogen removal from domestic wastewater," Environ. Sci-Wat Res., vol. 2, pp. 832-837, 2016.

[8] X. Cao, X. Huang, P. Liang, K. Xiao, Y. Zhou, X. Zhang, B. E. Logan, "A new method for water desalination using microbial desalination cells,” Envir. Sci. Tech., vol. 43, no. 18, pp. 7148-7152, 2009.

[9] Y. Qu, Y. Feng, X. Wang, J. Liu, J. Lv, W. He, B. E. Logan, "Simultaneous water desalination and electricity generation in a microbial desalination cell with electrolyte recirculation for $\mathrm{pH}$ control," Bioresource technol., vol. 106, pp. 89-94, 2012.

[10] S. Sevda, H. Yuan, Z. He, I. M. Abu-Reesh, "Microbial desalination cells as a versatile technology: functions, optimization and prospective," Desalination, vol. 371, pp. 9-17, 2015.

[11] A. C. Sophia, V. M. Bhalambaal, E. C. Lima, M. Thirunavoukkarasu, "Microbial desalination cell technology: Contribution to sustainable waste water treatment process, current status and future applications," Journal of Environmental Chemical Engineering, vol. 4, no. 3, pp. 3468-3478, 2016.

[12] A. Elawwad, "Optimized biological nitrogen removal of high-strength ammonium wastewater by activated sludge modelling," Journal of Water Reuse and Desalination, vol. 8, no. 3, pp. 393-403, 2018.

[13] A. Elawwad, M. Rageb, H. Abdel-Halim, "An economical, environmental and social comparison between vacuum and gravity sewers in decentralized sanitation systems, with Egypt as a case study," Journal of Water Sanitation and Hygiene for Development, vol. 5, no. 4, pp. 614-619, 2015. 